\title{
Patient Perspectives on Clinical Scribes in Primary Care
}

\author{
Chen Yan, $\mathrm{MD}^{7}$, Susannah Rose, $P h D^{2}$, Michael Rothberg, MD, MPH${ }^{3}$, Mary Beth Mercer, $\mathrm{MPH}^{2}$, \\ Kenneth Goodman, $\mathrm{MD}^{4}$, and Anita D. Misra-Hebert, MD, $\mathrm{MPH}^{3}$
}

${ }^{1}$ Residency, Department of Neurology, Neurological Institute, Cleveland Clinic, Cleveland, OH, USA; ${ }^{2}$ Office of Patient Experience, Cleveland Clinic, Cleveland, OH, USA; ${ }^{3}$ Center for Value-Based Care Research, Medicine Institute, Cleveland Clinic, Cleveland, $\mathrm{OH}$, USA; ${ }^{4} \mathrm{Department}$ of Family Medicine, Cleveland Clinic, Beachwood, OH, USA.

\author{
KEY WORDS: primary care; primary care redesign; doctor-patient \\ relationships. \\ J Gen Intern Med 33(11): 1859-61 \\ DOI: $10.1007 / \mathrm{s} 11606-018-4573-9$ \\ (c) Society of General Internal Medicine 2018
}

\section{INTRODUCTION}

Clinical scribes who are medical assistants or nurses may not only relieve the increased administrative burdens electronic health records place on primary care physicians but also bring benefits $^{1,2}$ in documentation quality, patient care, and team dynamics $^{3}$. In our previous qualitative study, patients associated clinical scribes with improved documentation quality and increased attention from their physicians ${ }^{3}$. While most were comfortable with the clinical scribe's presence, a few alluded to situations in which they would be uncomfortable ${ }^{3}$. Thus, to describe quantitatively patient opinions, we surveyed patients about their perspectives regarding clinical scribes in primary care.

\section{METHODS}

A 16-item questionnaire was developed iteratively with expert oversight from a committee of practicing physicians and health system researchers. This questionnaire was pilot tested with 10 patients. Data from pilot testing were not included in the final analysis. Based on patient feedback, the option of selecting N/A for possible uncomfortable topics was added.

A convenience sample of patients 18 years or older attending routine physician visits with a clinical scribe was recruited in person from 8 physician-scribe pairs at 4 clinics from April to July 2015. Questionnaires were administered on-site after the visit was completed. Patients who were cognitively impaired, unable to provide consent, or unable to speak English were excluded. This study was approved by the Cleveland Clinic Institutional Review Board.

\section{RESULTS}

All 123 recruited patients completed the questionnaire. Table 1 summarizes patient characteristics: 110 (89.4\%) were

Published online July 10, 2018 established patients; $72(58.5 \%)$ had prior clinical scribe exposure. Eighty-two $(66.7 \%)$ expressed no preference regarding the scribe's presence; 38 (30.9\%) preferred a scribe. All patients stated they would visit the physician again if the scribe was present.

Eighty-four $(68.2 \%)$ patients were very or extremely comfortable with a scribe of a different gender. Most patients were at least somewhat comfortable speaking with their physicians regarding smoking, alcohol use, drug use, and mental health concerns with or without a scribe. Sexual history was a notable exception (Table 2). Female patients $(40 / 43,79.1 \%)$ were more likely than male patients $(46 / 60,56.7 \%)$ to be at least somewhat comfortable discussing sexual topics in the presence of scribes $\left(\chi^{2} p<0.01\right)$.

The written record was very or extremely important for 85 (69.1\%) patients. Fifty-nine (48\%) patients perceived documentation to be more complete with the scribe present and 56 $(45.5 \%)$ noted no difference.

Eighty-four $(68.3 \%)$ patients perceived no difference in physician attention, $31(25.2 \%)$ perceived more physician attention, and $8(6.5 \%)$ perceived less with the scribe present.

\section{DISCUSSION}

Patients indicated no clear preference regarding the scribe's presence or difference in perceived amount of physician attention. As most were established patients, these results may indicate baseline high satisfaction with their physician. Many patients had prior exposure to a scribe visit and might have already acclimated, which may explain why our findings related to documentation quality and physician attention differed from previous qualitative work ${ }^{3}$. All patients would return for a visit with the physician even if the scribe remained, implying that patients may place more weight on their relationships with the physician than scribe presence. Further study should compare patient experiences with and without clinical scribes with focus on patients who decline scribes.

Though patients may be comfortable talking about most potentially sensitive topics in the presence of scribes ${ }^{4}$ in our study, sexual history presents a notable exception, particularly for male patients. Of note, all scribes in our study were female, potentially skewing our finding. Nonetheless, physicians may 
Table 1 Patient demographics

\begin{tabular}{ll}
\hline \hline Demographic & Number (\%), $\mathbf{n = 1 2 3}$ \\
\hline Location & \\
Site A & $26(21.1 \%)$ \\
Site B & $30(24.4 \%)$ \\
Site C & $29(23.6 \%)$ \\
Site D & $38(30.9 \%)$ \\
Age & \\
18-29 & $7(5.7 \%)$ \\
30-49 & $30(24.4 \%)$ \\
50-64 & $39(31.7 \%)$ \\
65 or over & $47(38.2 \%)$ \\
Gender & $54(43.9 \%)$ \\
Female & $69(56.1 \%)$ \\
Male & \\
Education & $33(26.8 \%)$ \\
High school & $14(11.4 \%)$ \\
Trade/technical/vocational school & $53(43.1 \%)$ \\
College & $15(12.2 \%)$ \\
Masters-level graduate training & $6(4.9 \%)$ \\
Doctoral-level graduate training & $2(1.6 \%)$ \\
Other & $23(1.6 \%)$ \\
Race & $3(2.4 \%)$ \\
American Indian or Alaska Native & $7(5.7 \%)$ \\
Asian & $0(0 \%)$ \\
Black or African-American & $109(88.6 \%)$ \\
Native Hawaiian or Other Pacific Islander & $23(1.6 \%)$ \\
White & $14(11.4 \%)$ \\
More than one race & $122(99.2 \%)$ \\
Ethnicity & \\
Yes, Hispanic or Latino/Latina & \\
No, not Hispanic or Latino/Latina & \\
Relationship with doctor & \\
< 1 year & \\
1-4 years & \\
5-9 years & \\
10-15 years & \\
$>15$ years & \\
\hline
\end{tabular}

Table 2 Patient comfort with scribe present (vs. not present). All values given in percent

\begin{tabular}{|c|c|c|c|c|c|c|}
\hline Topic & $\begin{array}{l}\text { Not at all } \\
\text { comfortable }\end{array}$ & $\begin{array}{l}\text { Not very } \\
\text { comfortable }\end{array}$ & $\begin{array}{l}\text { Somewhat } \\
\text { comfortable }\end{array}$ & $\begin{array}{l}\text { Very } \\
\text { comfortable }\end{array}$ & $\begin{array}{l}\text { Extremely } \\
\text { comfortable }\end{array}$ & $\begin{array}{l}p \\
\left(\chi^{2}\right)\end{array}$ \\
\hline Smoking $(n=70)$ & $1.4(1.4)$ & $2.9(1.4)$ & $4.3(2.9)$ & $2.4(2.3)$ & $67.1(71.4)$ & 0.96 \\
\hline Alcohol $(n=83)$ & $2.4(1.2)$ & $2.4(1.2)$ & $3.6(3.6)$ & $22.9(22.9)$ & $68.7(71.1)$ & 0.95 \\
\hline Drug use $(n=63)$ & $0(0)$ & $1.6(0)$ & $6.3(4.7)$ & $27.0(25.4)$ & $65.1(69.8)$ & 0.73 \\
\hline $\begin{array}{l}\text { Mental health }(n= \\
97)\end{array}$ & $2.06(1.03)$ & $5.15(1.03)$ & $5.15(6.19)$ & $29.9(23.7)$ & $57.7(68.0)$ & 0.33 \\
\hline $\begin{array}{l}\text { Sexual health }(n= \\
101)\end{array}$ & $4.0(1.0)$ & $11.9(2.0)$ & $17.8(22.8)$ & $20.8(22.8)$ & $45.5(51.5)$ & 0.04 \\
\hline
\end{tabular}

need to assess patient comfort level when discussing sexual history and consider offering to continue the visit without the scribe if needed. Future studies should evaluate patient-scribe gender discordance.

\section{Limitations}

Our use of a convenience sample of established patients with relative race and ethnicity homogeneity limits generalizability. Only patients who agreed to a scribe visit were available for sampling, which may lead to selection bias.

\section{CONCLUSIONS}

While not indicating a preference for clinical scribes, patients were willing to accept a clinical scribe as part of their primary care visit. Patients were comfortable with most topics except sexual history, which has implications for clinical practice.

Corresponding Author: Anita D. Misra-Hebert, MD, MPH; Center for Value-Based Care Research, Medicine Institute Cleveland Clinic, 9500 Euclid Avenue, G10, Cleveland, OH 44195, USA (e-mail: misraa@ccf. org). 
FUNDING INFORMATION Dr. Misra-Hebert receives funding from the Agency for Healthcare Research and Quality grant no. KOSHSO24128.

\section{COMPLIANCE WITH ETHICAL STANDARDS:}

This study was approved by the Cleveland Clinic Institutional Review Board.

Conflict of Interest: The authors declare that they do not have a conflict of interest.

\section{REFERENCES}

1. Arndt BG, Beasley JW, Watkinson MD, et al. Tethered to the EHR: Primary Care Physician Workload Assessment Using EHR Event Log Data and Time-Motion Observations. Ann Fam Med. 2017;15(5):419-426. https://doi.org/10.1370/afm.2121.
2. Bodenheimer T, Willard-Grace $\mathbf{R}$, Ghorob A. Expanding the Roles of Medical Assistants: Who Does What in Primary Care. JAMA Intern Med. 2014;174(7):1025-1026. https://doi.org/10.1001/jamainternmed.2014. 1319

3. Yan C, Rose S, Rothberg MB, Mercer MB, Goodman K, Misra-Hebert AD. Physician, Scribe, and Patient Perspectives on Clinical Scribes in Primary Care. J Gen Intern Med. 2016. https://doi.org/10.1007/s11606016-3719-x.

4. Koshy S, Feustel PJ, Hong M, Kogan BA. Scribes in an Ambulatory Urology Practice: Patient and Physician Satisfaction. J Urol. 2010;184(1):258-262. https://doi.org/10.1016/j.juro.2010.03.040. 